\title{
TEMPORAL AND SPATIAL VARIATION OF SOIL MOISTURE IN CHINA BASED ON SMAP DATA
}

\author{
Xianjian $\mathrm{Lu}^{1}$, Yuhui Huang ${ }^{1}$,Hongbo Yan $^{1 *}$, Chenlong $\mathrm{Wu}^{1}$, Le Luo ${ }^{1}$, Bin $\mathrm{Zhou}^{1}$ \\ ${ }^{1}$ Guilin University of Technology, College of Geomatics and Geoinformation, 541006, Guilin@glut.edu
}

KEY WORDS: Soil moisture; China; Temporal and spatial variation; Precipitation; Temperature; Correlation analysis

\begin{abstract}
:
Soil moisture is one of the most important indexes that affect crop growth and meteorological change. Widespread monitoring soil moisture is the forerunner of formulating better soil and water management measure and disaster mitigation strategies. Soil moisture $(0-10 \mathrm{~cm})$ of SMAP L3 from April 2015 to April 2018 was cited in this paper. The accuracy of SMAP L3 was compared and evaluated by real-time products of CLDAS-V2.0 from CMA Land Data Assimilation system. The results show that SMAP L3 can reflect the objective regular of soil moisture. In addition, the spatial and temporal variation characteristics of soil moisture $(0-10 \mathrm{~cm})$ at SMAP L3 are also analyzed, which show that the soil moisture is higher in the south than in the north and it is higher in the east than in the west of China. Moreover, the seasonal characteristics are as follows: The soil moisture is the highest in summer, and the second in autumn, while it is lower in winter and spring. Finally, based on the study of temperature and precipitation data from meteorological stations in China, it is found that there is a positive correlation between soil moisture and precipitation in south China, with a correlation coefficient of 0.5027 . There is a negative correlation between soil moisture and precipitation in Northeast and northwest China and in Qinghai-Tibet region. What's more, soil moisture has a positive correlation with temperature, with an average correlation coefficient of 0.6813 ; the highest correlation coefficient is 0.7752 in Northeast China.
\end{abstract}

\section{INTRODYTION}

Soil moisture combines with water, energy and carbon cycle; it is one of the important material or environmental conditions for the normal growth and development of crops (Zhang, 1982). It mainly comes from precipitation and irrigation. Plants absorb water directly from the soil through roots to maintain their life activities (Wang et al., 2004). Therefore, the water content in soil directly affects the growth ability of plants (Rong et al., 2009). The soil water content at a certain level in a certain period of time in a region is an important index for evaluating drought and irrigation. At the same time, meteorological factors also restrict the range of soil moisture change. The influence of temperature and precipitation on soil moisture are the most important among the meteorological factors such as light, temperature, precipitation, air humidity, wind direction and wind speed etc. (Fu et al., 2012). In the early 1980s, Zhang Jingbin defined and used traditional methods to monitor soil moisture as one of the important indicators of crop growth and meteorological change factors (Zhang, 1982). In order to improve the efficiency, advanced remote sensing methods began to appear in the study of soil moisture monitoring theory and methods. The improved thermal inertia method and vegetation water scarcity index method are the main representative methods (Miernecki et al., 2014). Passive microwave remote sensing, relying on soil sensitivity, has become the main modern means in monitoring soil moisture. Bai $\mathrm{Yu}$ carried out the authenticity test on two passive microwave soil moisture products including SMAP (Soil Moisture Active and Passive) and SMOS (Soil Moisture and Ocean Salinity), aiming at monitoring data of soil moisture sensor network in Jilin Province (Bai et al.,2018). The results showed that the RMS of both products were greater than 0.07 $\mathrm{m}^{3} \cdot \mathrm{m}^{-3}$.However, the unbiased root mean square error of SMAP
L3 passive microwave soil moisture products is slightly lower than that of the same type.

At present, soil moisture monitoring technology has been widely used in the field of drought, land use, agriculture and other practical analysis. Soil moisture products are various, such as SOMS, CLDAS, CLM3, SMAP L3, etc. SMAP L3 is a series of soil moisture products released by NASA in 2015, which can well cover the absolute soil moisture in the global region. The product is obtained by the single-channel vpolarized microwave algorithm (SCA-V) retrieval (Yan, 2014), and the retrieval error is less than $0.04 \mathrm{~m}^{3} / \mathrm{m}^{3}$ in the global scale, and its accuracy is reliable. Therefore, the study of SMAP L3 and its application has certain research value. It is another important means to monitor soil moisture by remote sensing.

\section{DATA RESOURCES AND STUDY AREA}

\subsection{SMAP L3 Soil Moisture Data}

The SMAP released by the Alaska Satellite Facility (ASF) and the National Snow and Ice Data Center (NSIDC) is at NASA Research Center. It is the world's first active and passive microwave (L-band) soil moisture monitoring satellite designed by NASA, and it was launched from the Goddard space flight center on January 31, 2015. Now, SMAP L3 soil moisture collected from the national snow and ice data center (NSIDC) temporarily has three products :(1) passive L-band radiometer $36 \mathrm{~km}(1.41 \mathrm{GHZ}) ;(2)$ active l-band radar at $3 \mathrm{~km}(1.26$ $\mathrm{GHZ}$;(3) $9 \mathrm{~km}$ active/passive L-band combination product. The main purpose of SMAP is to learn the mutual processes of water, energy and carbon cycle, estimate the global surface water and heat flux, quantify the net carbon flux in the northern hemisphere, improve the meteorological forecasting ability and develop the ability to improve flood forecasting and drought monitoring (Jing et al.,2009). On July 7, 2015, its active radar

\footnotetext{
${ }^{*}$ Corresponding author
} 
sensor was damaged, so that SMAP can only release the passive microwave soil moisture product of $36 \mathrm{~km}$ to the public. This product adopts the single-channel v-polarized microwave algorithm (SCA-V) (Guo et al., 2013). The retrieval error is less than $0.04 \mathrm{~m}^{3} / \mathrm{m}^{3}$ on the global scale (http://ismn.geo.tuwien.ac.at/ismn/). The data selected in this paper includes the daily SMAP L3 levels of soil moisture products from April 2015 to April 2018, ranging from $73^{\circ} 33^{\prime}$ to $135^{\circ} 05^{\prime} \mathrm{E}, 3^{\circ} 51$ 'to $53^{\circ} 33^{\prime} \mathrm{N}$, which contain 31 provincial administrative regions in China. The spatial resolution is $36 \mathrm{~km}$.

\section{2（CLDAS-V2.0） Real-time Soil Moisture Data}

The real-time product data set of the land data assimilation system (cldas-v2.0) of China meteorological administration (CMA) is a new generation product released by China meteorological data network in 2017. CLDASV2.0 products cover Asia regions $\left(0-65^{\circ} \mathrm{N}, 60-160^{\circ} \mathrm{E}\right)$, with the spatial resolution of $0.0625^{\circ}$. The products include atmosphere driven products, surface temperature analysis products, soil moisture, soil temperature analysis products and relative soil moisture analysis products, which download from (http://data.cma.cn/). The data set used a variety of sources on the ground, such as satellite observation data, adopted multiple grid vibrational assimilation (STMAS) (Zeng et al.,2016), the optimal interpolation (OI) (Li et al.,2010), matching probability density function (CDF)(Yin et al.,2018), physical retrieval methods (Latimer et al.,2014,Wei et al.,2005) ,and terrain correction technology. The data quality is better than that of the similar international products in China area.

\subsection{Daily Ground Climate Data in China (V3.0)}

The daily ground climate data includes atmospheric pressure, temperature, precipitation, evaporation, relative humidity, wind direction and velocity, sunshine time and geothermal elements of 824 benchmark weather stations in China since January 1951, which are shown in Figure 1 (Gong et al.,2014): The data is the latest precipitation and temperature data of the ground stations, which is download from the National Meteorological Information Center, ranging from $73^{\circ} 33^{\prime}-135^{\circ}$ $05^{\prime} \mathrm{E}, 3^{\circ} 51^{\prime}-53^{\circ} 33^{\prime} \mathrm{N}$.

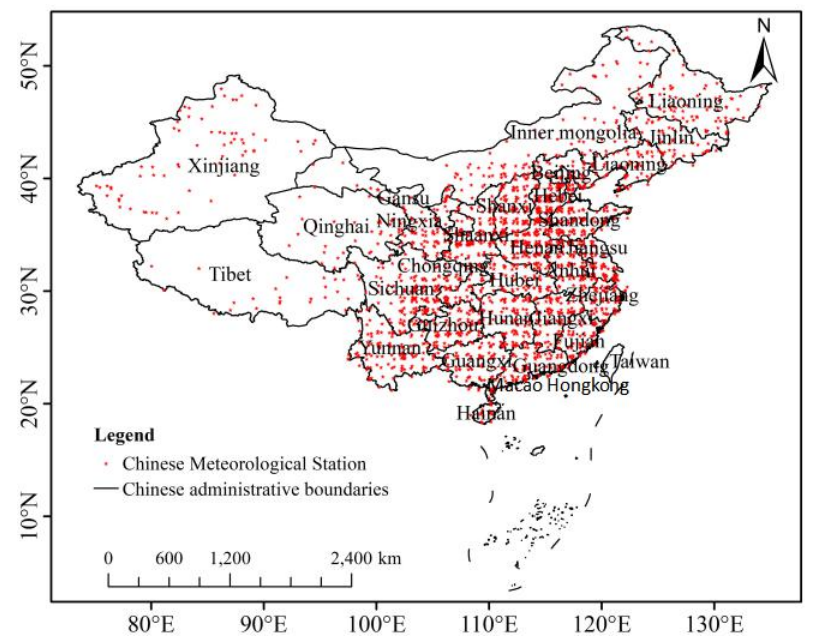

Figure 1 Distribution map of the meteorological stations in China

\subsection{Study Area}

China is located in the northern hemisphere. The north and the south of China are $5500 \mathrm{~km}$ apart; the east and the west of China are $5200 \mathrm{~km}$ apart, and about 50 degrees apart from the north to the south. The four ends of the Chinese territory are: to the east is Heilongjiang Province $\left(135^{\circ} 02^{\prime} 30 " \mathrm{E}\right)$; to the west is the Pamir Plateau $\left(73^{\circ} 29^{\prime} 59.79 " \mathrm{E}\right)$; to the south is Zengmu ( $3^{\circ}$ $\left.31^{\prime} 00^{\prime \prime} \mathrm{N}\right)$, and to the north is Mohe $\left(53^{\circ} 33^{\prime} \mathrm{N}\right)$. With an area of 9.6 million square kilometers, it ranks third in the world $\mathrm{Xu}$ et al., 2008). Generally speaking, it is high in the west and low in the east. The climate change in China is across five temperate zones: cold temperate, middle temperate, warm temperate, subtropical and tropical (Sha et al., 2002). Meanwhile, China's monsoon climate is characterized by dry winters and rainy summers. All kinds of climate bring rich and colorful natural climate landscape to China. As far as the economy concerned, the industry has been increasing steadily. The government revenue is mainly from industry, supplemented by agriculture, and the tertiary industry is developing rapidly. As the world's second largest economy, China's economy continues to rise, growing 6.6\% in 2018 compared with the same period last year (Li et al., 2008). In order to better analyze the spatial and temporal variation of soil moisture in China, it is divided into four geographical areas: Northeast, South, Qinghai-Tibet and Northwest (Figure 2), according to the geographical location, topography, climate and socioeconomic characteristics of China.

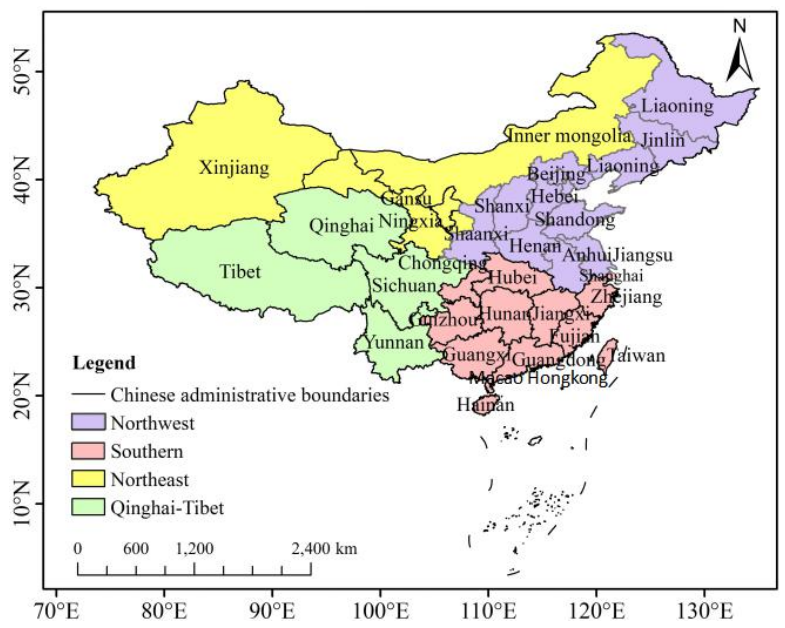

Figure 2 Geographical Division Map of Chinese Provinces

\section{PRECISION COMPARISON OF TWO SOIL MOISTURE PRODUCTS}

At present, the products of soil moisture in China mainly include reanalysis products and soil moisture retrieved by satellite microwave remote sensing. Among them, SMAP L3 is the latest L-band satellite soil moisture products, which are used for soil moisture monitoring publicly (The data is only calculated in mainland China, excluding Hong Kong, Macau, Taiwan). Domestic and foreign scholars have carried out a large number of assessment work on it, which plays a certain role in regional drought assessment and agricultural development. SMAP L3 and CLDAS-V2.0 are different spatial scales of real-time products. The unit of soil moisture of CLDAS products is weight water content, while that of SMAP L3 products is volume water content(Xu et al.,2017). In WGS 
84 coordinate system, the two kinds of data sets were used to compare and analyze the soil moisture for each province ( $\mathrm{Li}$ et al., 2017). It can reduce the influence of spatial scale differences on evaluation to some extent. CLDAS soil moisture products were used as the standard in this paper.

As shown in Table 1, the correlation coefficient of 14 provinces is as high as 0.9 , accounting for $42 \%$, and the standard deviation of 21 provinces is less than $0.05 \mathrm{~mm}^{3} \mathrm{~mm}^{-3}$, accounting for $60 \%$. It proves that the SMAP L3 soil moisture products can reflect the objective change of soil moisture with CLDAS as the reference. However, The standard deviations of Tibet, Heilongjiang, Inner Mongolia, Ningxia and other provinces are all greater than $0.50 \mathrm{~mm}^{3} \cdot \mathrm{mm}^{-3}$, because these provinces are located in cold regions, the observation stations are sparsely distributed, the environment is harsh, and the water in the soil is frozen in winter, which affects the performance of the instrument.

\begin{tabular}{|c|c|c|c|c|c|c|c|}
\hline Province & $\begin{array}{l}\text { Correlation } \\
\text { Coefficient }\end{array}$ & $\begin{array}{c}\text { Deviation / } \\
\left(\mathrm{mm}^{3} \cdot \mathrm{mm}^{-3}\right)\end{array}$ & $\begin{array}{c}\text { RMSE / } \\
\left(\mathrm{mm}^{3} \cdot \mathrm{mm}^{-3}\right)\end{array}$ & Province & $\begin{array}{l}\text { Correlation } \\
\text { Coefficient }\end{array}$ & $\begin{array}{c}\text { Deviation / } \\
\left(\mathrm{mm}^{3} \cdot \mathrm{mm}^{-3}\right)\end{array}$ & $\begin{array}{c}\mathrm{RMSE} / \\
\left(\mathrm{mm}^{3} \cdot \mathrm{mm}^{-3}\right)\end{array}$ \\
\hline Zhejiang & 0.955 & 0.009 & 0.012 & Henan & 0.701 & -0.032 & 0.046 \\
\hline Yunnan & 0.767 & -0.036 & 0.051 & Beijing & 0.906 & -0.008 & 0.011 \\
\hline Xinjiang & 0.688 & -0.020 & 0.028 & Tianjin & 0.607 & 0.055 & 0.078 \\
\hline Tibet & 0.724 & -0.025 & 0.035 & Hainan & 0.667 & 0.078 & 0.110 \\
\hline Sichuan & 0.808 & -0.028 & 0.040 & Guizhou & 0.796 & -0.036 & 0.051 \\
\hline Shaanxi & 0.692 & -0.033 & 0.047 & Guangxi & 0.901 & -0.017 & 0.024 \\
\hline Shanxi & 0.556 & -0.041 & 0.058 & Gansu & 0.713 & -0.024 & 0.034 \\
\hline Shandong & 0.911 & -0.009 & 0.013 & Fujian & 0.921 & -0.016 & 0.022 \\
\hline Qinghai & 0.982 & 0.002 & 0.002 & Anhui & 0.910 & 0.014 & 0.020 \\
\hline Ningxia & 0.403 & -0.045 & 0.064 & Shanghai & 0.619 & 0.100 & 0.141 \\
\hline $\begin{array}{c}\text { Inner } \\
\text { Mongolia }\end{array}$ & 0.632 & -0.028 & 0.039 & Chongqing & 0.809 & -0.035 & 0.050 \\
\hline Liaoning & 0.970 & -0.003 & 0.004 & Jiangsu & 0.732 & 0.048 & 0.068 \\
\hline Jiangxi & 0.936 & 0.013 & 0.018 & Guangdong & 0.987 & 0.002 & 0.003 \\
\hline Jilin & 0.920 & -0.010 & 0.014 & Hebei & 0.658 & -0.029 & 0.041 \\
\hline Hunan & 0.980 & -0.004 & 0.005 & Heilongjiang & 0.935 & 0.009 & 0.013 \\
\hline Hubei & 0.994 & -0.001 & 0.001 & & & & \\
\hline
\end{tabular}

Table 1 Soil Moisture Simulation Results on 2016 were evaluated by Province

\section{SPATIAL DISTRIBUTION OF SOIL MOISTURE IN CHINA}

According to the SMAP L3 processing method and the standard document of the People's Republic of China in2014 (Ji et al., 2014), soil moisture in the study area can be divided into eight grades: $0-0.2$ is extreme drought; 0.2 to 0.4 is drought; $0.4-0.6$ is normal; $0.6-0.8$ is wet; 0.8 to 1.0 is extreme wet. The distribution map below is classified strictly based on the weather color standard file.

\subsection{Seasonal Variation}

The spatial distribution of soil moisture in China from April 2015 to April 2018 is shown in Figure3.The spatial distribution of soil moisture in spring (March to May) is shown in Figure 3a in summer (June to August) is shown in Figure 3b, in autumn
(September to December) is shown in Figure 3c and in winter (February to November next year) is shown in Figure 3d. It can be seen from the distribution of seasonal average soil moisture that the wettest season is summer, followed by autumn, and the dry season is winter. The distribution is characterized by the Yangtze River as the boundary; there is a great difference between the north and the south. Because of the deserts and snow in the regions of Xinjiang, Tibet and Inner Mongolia, soil moisture is often low for a long time, while the upper to the Yangtze River, soil moisture is quite abundant. The results show that SMAP L3 can reflect the main spatial distribution characteristics of soil moisture and have a good consistency in China.

Generally speaking, the distribution of soil moisture in the four seasons is different. Large areas of soil in Xinjiang, Tibet and Inner Mongolia are short of moisture, while the southern region is wet all the year round, especially in coastal areas, which is in line with China's actual situation. 


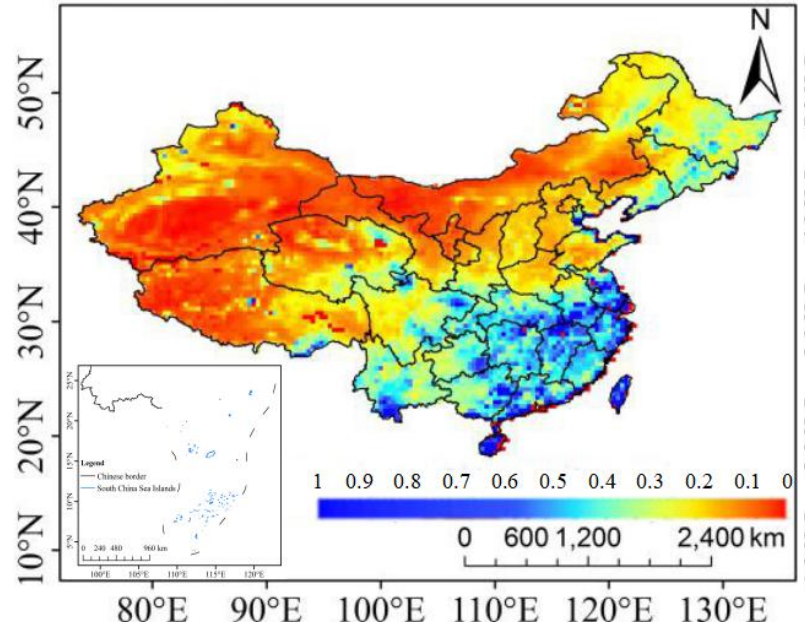

a) Spring

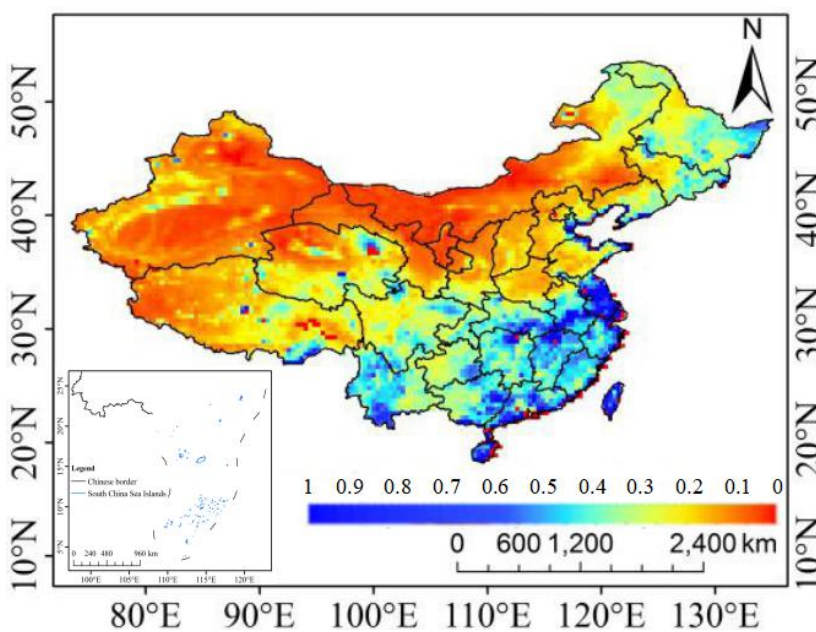

c) Autumn
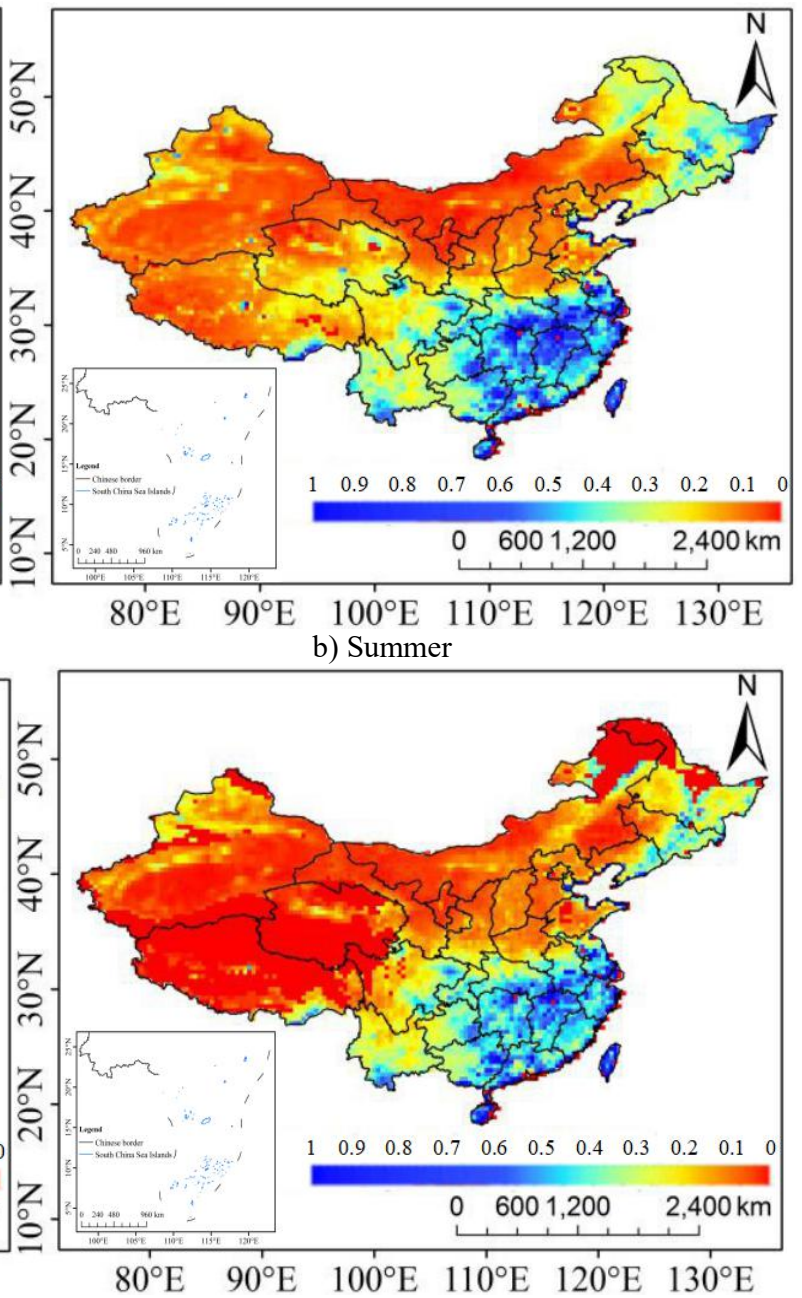

d) Winter

Figure 3 Quarterly Average Distribution Map of Soil Moisture in China

\subsection{Annual Variation}

Figure4 shows the annual average distribution of soil moisture in China in 2016 and 2017. It can be seen that the distribution of soil moisture in these two years are roughly the same, and soil moisture is generally stable, showing a north-south difference. The soil moisture decreased gradually from east to west and from south to north.
(1) The central region of Tibet is dry all year round, while the eastern border region rises, possibly because the melting of permafrost has increased average soil moisture as global temperatures have risen in recent years.

(2) The wet area of soil on both sides of the Yangtze River is shrinking toward the river, in part because of the decrease of inland tributaries.

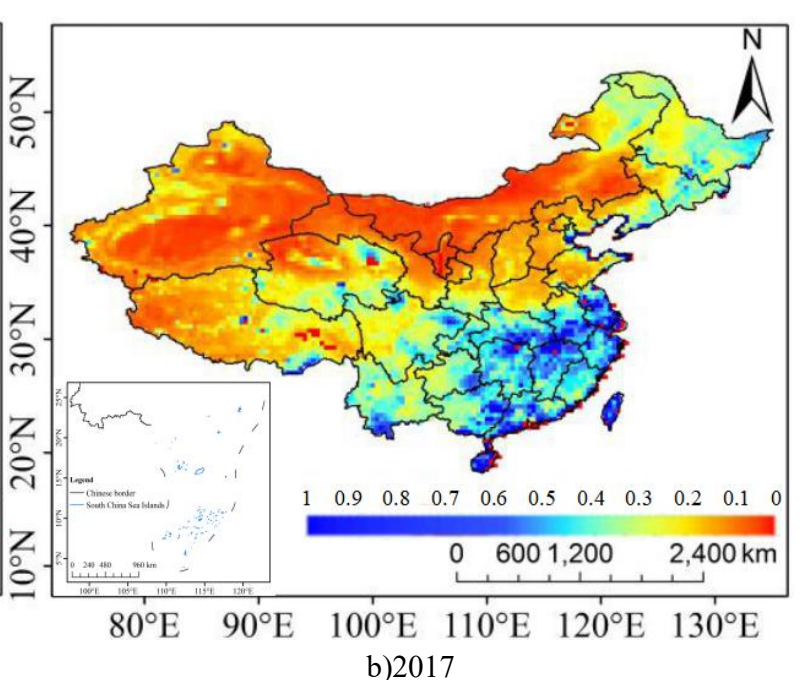

Figure 4 Annual Distribution of Mean Soil Moisture in China in 2016 and 2017 


\section{INFLUENCE OF TEMPERATURE AND PRECIPITATION ON THE SOIL MOISTURE}

In conclusion, In conclusion, the change of soil moisture distribution in different regions of China is similar, but the time of soil evolution in different regions is not consistent. In general, the meteorological factors that affect the soil moisture include precipitation, temperature, evaporation, air humidity, wind speed, sunshine, etc. (Ji et al., 2014). In this paper, temperature and precipitation are selected to analyze the effect on soil moisture change.

\subsection{Correlation and Test of Soil Moisture with Precipitation and Temperature}

The change of soil moisture is influenced by multiple factors, and in a short time scale, it is mainly controlled by precipitation (Cheng et al., 2008). The linear regression equation and correlation coefficient of soil moisture and precipitation in four geographical regions of China were calculated, as shown in Figure 5. It can be concluded from Figure 5 that the scatter plot

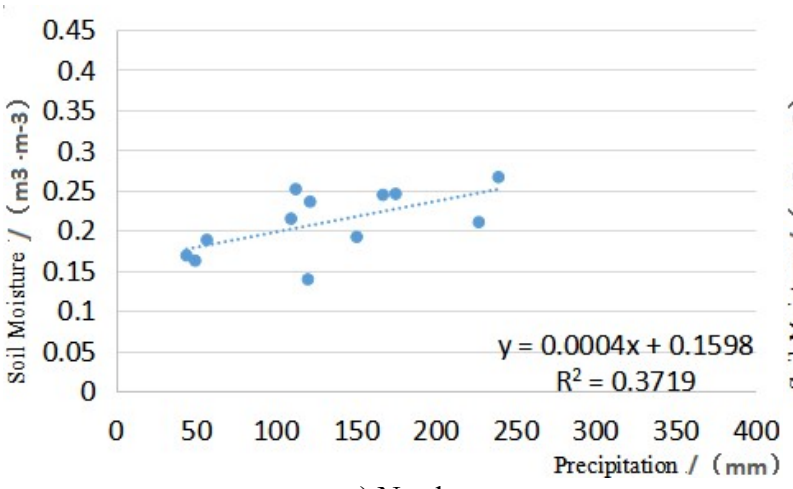

a) Northeast

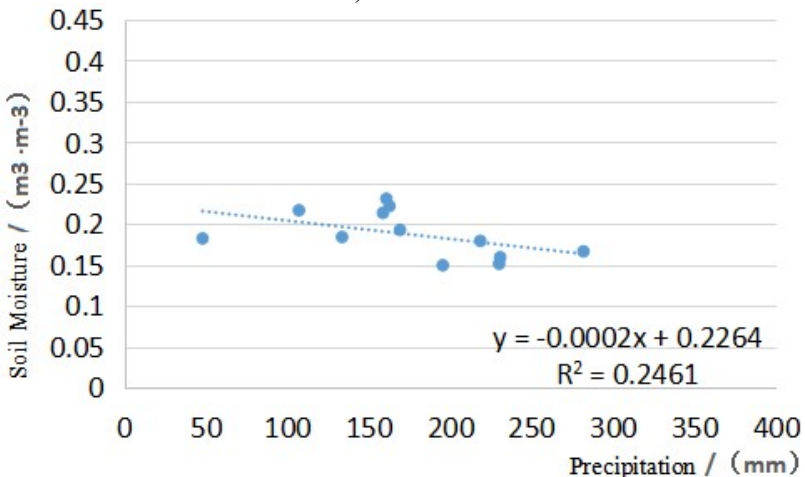

c) Qinghai-Tibet of soil moisture and precipitation in northeast China is sparse, and the precipitation has little influence on the soil moisture. The winter in northeast China is very cold, and the soil water is solid.Figure 5a shows that the correlation coefficient is 0.37.which proves that Soil moisture is affected by precipitation in southern. In Figure 5b, because the climate in the south is warm and the precipitation is abundant, the scatter plots of soil moisture and precipitation are relatively stable, which proves that the change of soil moisture is closely related to precipitation. Figure $5 \mathrm{c}$ shows that the distribution of soil moisture and precipitation scatter plot in Qinghai-Tibet region is unbalanced. The correlation coefficient is the smallest in all regions of the study area. In Qinghai-Tibet region, there are many rivers and most of the rivers are in plateau. In most areas, perennial frozen soil, precipitation will not cause changes in soil moisture, while in summer, little rain and weak changes in soil moisture. Figure 5d shows that the correlation coefficient between soil moisture and precipitation in Northwest is small, because the evapotranspiration in the Northwest is the highest in China. It is windy and dry all the year round, which causes precipitation to invade the soil surface in a short period of time and evaporate into water vapor, so the change of soil moisture is not obvious.
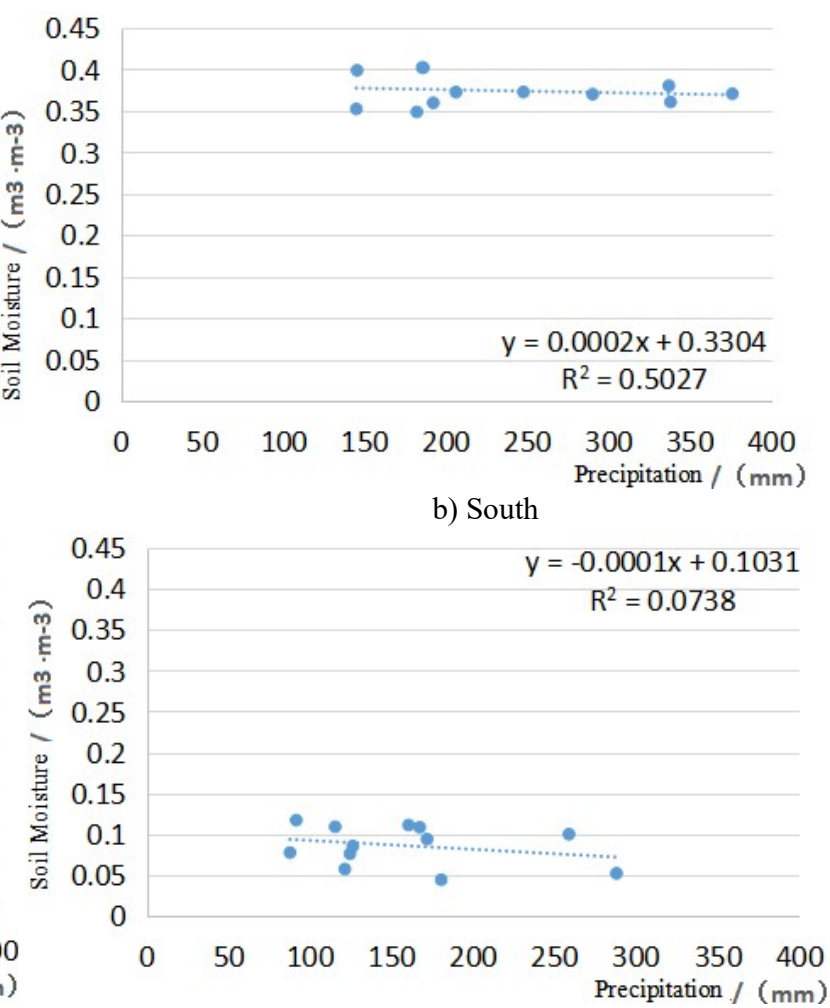

Figure 5 The linear relationship between soil moisture and precipitation

As shown in Table 2, there is a significant correlation between $0-10 \mathrm{~cm}$ surface soil moisture and precipitation in northeast and south, while it is not significant in other regions through $99 \%$ confidence interval. The increase of soil moisture and air temperature, the enhancement of surface heat dissipation and the increase of atmospheric moisture content will facilitate the formation of precipitation, which makes the correlation significant between soil moisture and precipitation in northeast and southern regions. $99 \%$ confidence is adopted to prove that the higher the precipitation, the higher the soil moisture.

\begin{tabular}{ccc|lcc}
\hline & Precipitation & \multicolumn{3}{c}{ Temperature } \\
\hline Region & F or T & F Value & Region & F or T & F Value \\
Northeast & T & 5.9116 & Northeast & T & 34.4839 \\
Southern & T & 10.1086 & Southern & F & 0.00501 \\
Qinghai-Tibet & F & 3.2644 & Qinghai-Tibet & T & 12.873 \\
Northwest & F & 0.7968 & Northwest & T & 23.9905 \\
\hline
\end{tabular}

(Note: $\mathrm{F}>4.10$, the correlation is significant.)

Table 2 The Correlation between Soil Moisture and Precipitation and Temperature 
Similarly, the $99 \%$ confidence interval is used to determine the consistency of soil moisture and temperature peaks and valleys, and to infer the correlation between them. The scatter diagrams of the relationship between soil moisture and temperature are shown in Figure 6.The scatter points are concentrated on the trend line in Figure 6a, which indicate that soil moisture and temperature are closely related in Northeast China. Figure 6b shows that the correlation coefficient between soil moisture and temperature in the south is low. It can be concluded that the soil

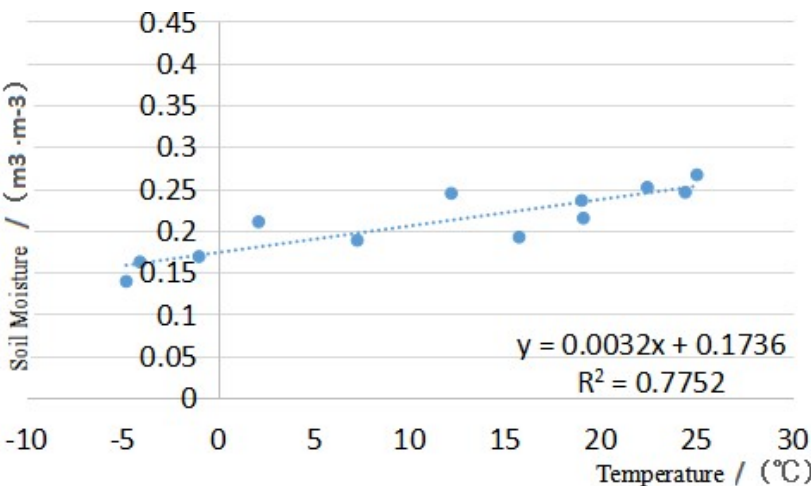

a) Northeast

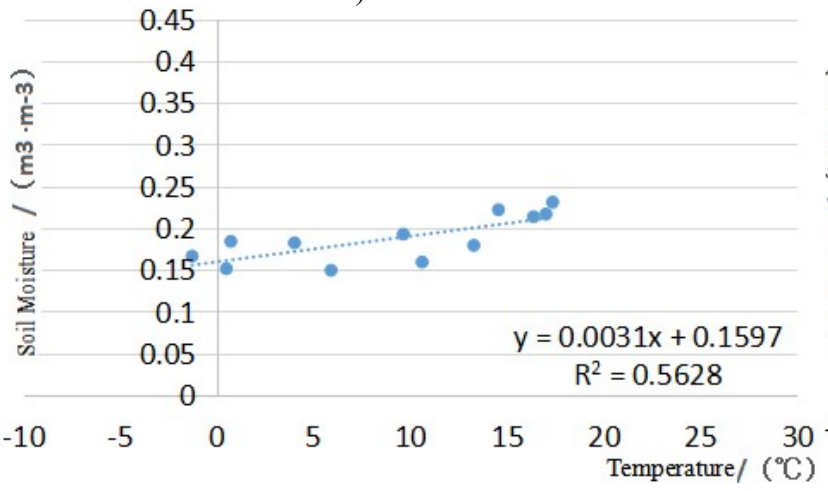

C) Qinghai-Tibet moisture and temperature in the Tibetan Plateau and Northwest China are significantly correlated. Figure $6 \mathrm{c}$ shows that there is correlation between soil moisture and temperature, and the change of temperature has effect on soil moisture, because of permafrost in Qinghai-Tibet region. But, Figure 6d shows that soil moisture in southern China is closely related to temperature. Therefore, conclusions can be drawn that there is a positive correlation between soil moisture and temperature in the northeast, Qinghai, and northwest regions, while it is not obvious in the South.

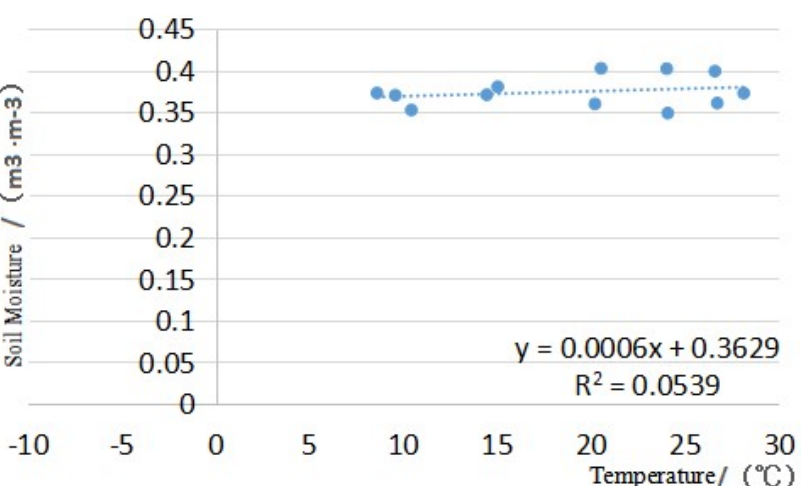

b) South

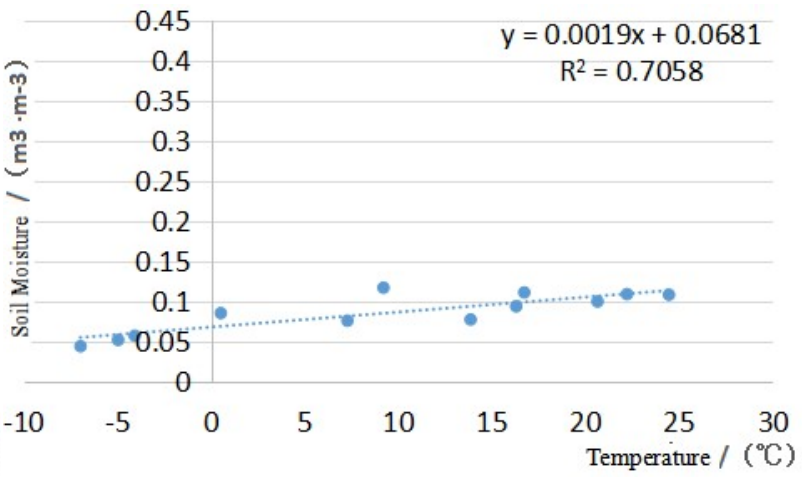

d) Northwest

Figure 6 the linear relationship between soil moisture and temperature

\section{CONCLUSIONS}

The soil moisture in China from April 2015 to April 2018 was analyzed in this paper. Considering the inaccuracy of soil temperature retrieval results in the frozen state, real-time products of GLDAS-V2.0 were used to evaluate SMAP L3. The monthly average, quarterly average and annual average soil moisture were calculated; the seasonal and annual average spatial distribution characteristics of soil moisture and the correlation between soil moisture and climatic factors were analyzed. The main conclusions are as follow:

1) The correlation coefficient between the results of SMAP L3 and the GLDAS-V2.0 products is relatively high in most provinces of China. The correlation coefficient of $90 \%$ of the provinces is above 0.6 , and the average standard deviation of most provinces is about $0.03 \mathrm{~mm}^{3} \cdot \mathrm{mm}^{-3}$.
2) The spatial and temporal variation characteristics of soil moisture at SMAP L3 were analyzed, which showed that the soil moisture is higher in the south than in the north and it is higher in the east than in the west of China. The highest in summer, followed by autumn, the third in spring, and the driest in winter.

3) It is found that there is a positive correlation between soil moisture and precipitation in southern, with a correlation coefficient of 0.5027 . There is a negative correlation between soil moisture and precipitation in Northeast and northwest China and in Qinghai-Tibet. For temperature, soil moisture has a positive correlation with temperature, with an average correlation coefficient of 0.6813 except in the southern region; the highest correlation coefficient is 0.7752 in Northeast China.

Although the quality of SMAP L3 is better than other remote sensing data of soil moisture, it needs to be analyzed with higher resolution and parametric scheme according to actual situations. Optimizing model, increasing time range, and 
selecting appropriate factors to prove the correlation will be studied in the further.

\section{REFERENCES}

Cheng S. The effect of temperature and precipitation on global soil moisture changes [D]. Lanzhou: Lanzhou University, 2017.

Bai Y, Meng Z, Zhao K, et al. Pixel-scale soil moisture monitoring network and its preliminary verification results for L-band soil moisture products [J]. Remote Sensing Technology and Applications, 2018, 33(1): 78-87.

Fu X, Song C, Zhong X. Analysis of soil moisture change in the northern Tibetan Plateau [J]. Advances in Water Science, 2012, 23(4): 64-474.

Guo P. Passive microwave soil moisture retrieval based on SMAP [D]. Beijing: University of Chinese Academy of Sciences, 2013.

Gong W. CMA Land Surface Data Assimilation System (CLDAS) Product Evaluation [D]. Nanjing: Nanjing University of Information Science and Technology, 2014.

Ji C. Meteorological standardization information service and management platform design [J]. China Standardization, 2014(4): 80-83.

Jing S. Research on the influence of surface characteristics based on remote sensing on surface water heat flux [D]. Beijing: Tsinghua University, 2009.

Latimer R, Risk D A. .A Physical retrieval Approach for Determining True Temperature Sensitivity of Respiration from High-frequency Soil CO2 Datasets[C]. San Francisco: AGU Fall Meeting. AGU Fall Meeting Abstracts, 2014: 39-45.

Li C. Research on population zoning model of mainland China based on GIS [D]. Lanzhou: Lanzhou University, 2008.

Li W, Xie Y, Deng S M, et al. Application of the Multigrid Method to the Two-Dimensional Doppler Radar Radial Velocity Data Assimilation[J]. Journal of Atmospheric \& Oceanic Technology, 2010, 27(27): 319-332.
Lhuang W, Zhang L, Li P, An Improved Topographic Correction Approach for Satellite Image [J]. Journal of Image and Graphics, 2005, 10(9): 1124-1128.

Miernecki M , Wigneron J P , Lopez-Baeza E, et al. Comparison of SMOS and SMAP soil moisture retrieval approaches using tower-based radiometer data over a vineyard field [J]. Remote Sensing of Environment, 2014, 154(1): 89-101.

Rong X, Wang B Song C, et al. Effects of some physical properties of soil on plant root growth [J]. Grass and Livestock, 2009, (10): 0001-0003.

Wang Y, Ren X, Yang J. Soil water research in water-saving agriculture $[\mathrm{J}]$. Progress in Water Resources and Hydropower Technology, 2004, (S1): 44-47.

Xu Y, Ren C, Ma X. Comparative analysis of multi-time scale drought variation characteristics in Northeast China based on SPI/SPEI index [J]. Arid Zone Research, 2017, 34(6): 12501262.

Yang T. China's regional multi-source active and passive remote sensing soil moisture product fusion research [J]. Nanjing University of Information Science and Technology, 2014, 11 (2): 317-318.

Yin $\mathrm{J}$, Zhan $\mathrm{X}$. Impact of Bias-Correction Methods on Effectiveness of Assimilating SMAP Soil Moisture Data into NCEP Global Forecast System Using the Ensemble Kalman Filter[J]. IEEE Geoscience \& Remote Sensing Letters, 2018, PP(99): 1-5.

Zhang J. Basic knowledge of agricultural meteorology [M]. Nanjing: Jiangsu Science and Technology Press, 1982.

Zeng J, Chen K S, Bi H, et al. A Preliminary Evaluation of the SMAP Radiometer Soil Moisture Product Over United States and Europe Using Ground-Based Measurements[J] . IEEE Transactions on Geoscience \& Remote Sensing, 2016, 54(8): 4929-4940.

Sha W, Shao X, Huang M. China's climate warming since the 1980 s and its impact on the boundaries of natural areas [J]. Chinese Science: Earth Science, 2002, 32(4): 317-326. 